$$
\text { Pontifícia Universidade C Católica }
$$

Maria Teresa Ferreira Bastos

Uma investigação na intimidade do portrait fotográfico

Tese de Doutorado

Tese apresentada ao Programa de Pós-graduação em Letras do Departamento de Letras da PUC-Rio como parte dos requisitos parciais para obtenção do título de Doutor em Letras.

Orientadora : Profa. Marília Rothier Cardoso

Rio de Janeiro

Março de 2007 


$$
\text { Pontifícia Universidade C Católica }
$$

Maria Teresa Ferreira Bastos

\section{Uma investigação na intimidade do portrait fotográfico}

Tese apresentada como requisito parcial para obtenção do grau de Doutor pelo programa de Pós-Graduação em Letras do Departamento de Letras do Centro de Teologia e Ciências Humanas da PUC-Rio. Aprovada pela Comissão Examinadora abaixo assinada.

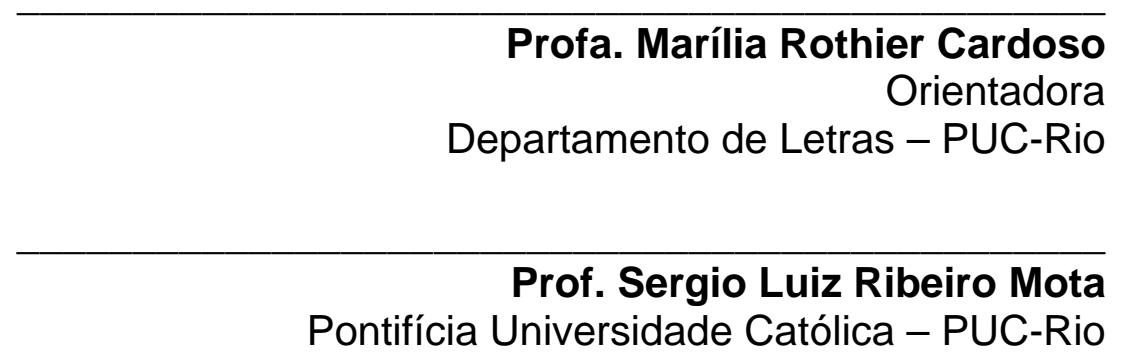

Profa. Eneida Maria de Souza

Faculdade de Letras - UFMG

Prof. Maurício Lissovsky

Departamento de Expressão e Linguagem - UFRJ

Prof. Roberto Corrêa dos Santos Instituto de Artes - UERJ

Prof. Paulo Fernando Carneiro de Andrade
Coordenador Setorial do Centro de Teologia
e Ciências Humanas - PUC-Rio

Rio de Janeiro, de de 
Todos os direitos reservados. É proibida a reprodução total ou parcial do trabalho sem autorização da universidade, da autora e da orientadora.

\section{Maria Teresa Ferreira Bastos}

Graduada em jornalismo pela PUC/MG e Mestre em Letras pela PUC-Rio. Trabalha na interseção texto escrito e imagem fotográfica. Atua profissionalmente como jornalista, fotógrafa e pesquisadora. Parte de seus estudos de doutorado foram feitos em Paris, França, no Laboratoire d'Histoire Visuelle Contemporaine da École des Hautes Études em Sciences Sociales.

Ficha Catalográfica

\section{Bastos, Maria Teresa Ferreira}

Uma investigação na intimidade do portrait fotográfico / Maria Teresa Ferreira Bastos ; orientadora: Marília Rothier Cardoso. - 2007.

$$
244 \text { f. ; } 30 \mathrm{~cm}
$$

Tese (Doutorado em Letras) - Pontifícia Universidade Católica do Rio de Janeiro, Rio de Janeiro, 2007.

Inclui bibliografia

1. Letras - Teses. 2. Portrait fotográfico. 3. Semelhança. 4. Intimidade. 5. Biografia. 6. Autobiografia. 7. Representação. I. Cardoso, Marília Rothier. II. Pontifícia Universidade Católica do Rio de Janeiro. Departamento de Letras. III. Título. 
Ao Bertinho, que me fez despertar para a fotografia e para os livros.

A Cris, minha primeira modelo e cúmplice nas criações fotográficas. 


\section{Agradecimentos}

À Marília Rothier, minha orientadora, que através de nossos reveladores encontros e longos e-mails esteve sempre presente em minha pesquisa, tornandose pacientemente minha primeira leitora, mãe e amiga eterna, além de professora sensível, inteligente, perspicaz e doce.

A André Gunthert, meu orientador-francês, pela generosa acolhida na Ecole des Hautes Etudes en Scienses Sociales, fundamental para o desenvolvimento das minhas pesquisas e também pela argúcia da orientação, receptividade e carinho, além das aulas preciosas.

A Fernando, pela dedicação, companheirismo, amor e, sobretudo, pela paciência. E ainda, pela compreensão, ajuda e pelos momentos vividos em Paris.

A Camilo, que colabora e participa tão compreensivelmente de minhas escolhas e que, nos instantes mais importantes do meu processo criativo, conseguiu esperar.

A Roberto Corrêa dos Santos, pelos pensamentos, sempre.

A Karl Erik Schollhammer, pelas aulas iluminadas e pelo estímulo às avessas.

A Ana Kiffer, pelas aulas maravilhosas e pela disponibilidade.

A Chiquinha, pela gentileza e competência habituais e ao secretariado do Departamento de Letras pela amabilidade. A Márcia Guerra pela ajuda na finalização da tese.

Aos meus amigos e amigas, colegas, pela convivência e troca. Em especial, a Marília Barcellos, que devemos à França a nossa amizade; a Danusa Depes, companheira de intermináveis conversas tendo a fotografia como fio e pela ajuda no trabalho braçal do fim da tese; a Cecilia Wellish com a qual compartilhei momentos de muita sabedoria; a Sérgio Barcellos, pela afinidade e sensibilidade; a Elisabeth Muylaert, pelo estímulo intelectual; a Ana Utsch pela cumplicidade e descobertas em Paris; a João Castelo Branco, pela parceria nas frias tardes de aula na França; à Gláucia, pela receptividade e franqueza habituais; a Olivier Petit, pela generosidade e pelas ótimas aulas de francês. A Carla Dias e Leila Duarte, pela oportunidade de trabalho e tolerância.

À Patrícia Ridolfi por ter-me aberto as portas do Departamento de Manuscritos da Biblioteca Nacional francesa.

A Paul-Louis Robert, Thierry Gervais e Carole Troufleay pela gentil acolhida na Societé Française de Photographie. 
À école Perceval, em especial à Madame Nuez, por ter recebido o Camilo com tanta disponibilidade e com isso ter me permitido estudar e pesquisar na França com dedicação.

À Maya, Leo, Olivier Castaing, Olivier Marty, Françoise e Dino Monteiro, Stépanie e Ricardo Vilas, Madame Françoise Esquisse, Pascal Le Peletier, Alain Riwain, Béatrice, Madeleine Ducamp, Cherif Chalakani e todos os amigos brasileiros e franceses que com solidariedade e afeto tornaram nossa vida em Paris possível.

Aos meus pais, Liz e Gilberto, pelo amor incondicional, educação e exemplo.

À minha grande família mineira, pelo amor de sempre, dedicação e grande apoio para a viagem à França. Em especial, Ana Liz, Felipe, Cristina Lucinda e Selma por cuidarem tão bem do meu filho na minha ausência. E a Sandro e Beth pelos livros em Paris!!!

A Zé Maria, Thereza e Patrícia Rabelo pelo apoio e carinho.

A Ecole des Hautes Etudes em Sciences Sociales pelo intercâmbio tão importante para o desenvolvimento da Pesquisa.

A Banca Examinadora composta por Eneida Maria de Souza, Maurício Lissovisky, Roberto Corrêa dos Santos e Sérgio Mota que me proporcionou uma defesa calorosa, porém tranqüila, emcocinante e forte.

A CAPES, CNPQ e à PUC-Rio, pelos auxílios financeiros concedidos, sem os quais este trabalho não poderia ter sido realizado. 


\section{Resumo}

Bastos, Maria Teresa Ferreira; Cardoso, Marília Rothier (Orientadora). Uma investigação na intimidade do portrait fotográfico. Rio de Janeiro, 2007. 244p. Tese de Doutorado - Departamento de Letras. Pontifícia Universidade Católica do Rio de Janeiro.

Esta tese dirige seu foco para o portrait fotográfico, examinando-o enquanto um gênero de reprodução da imagem e enquanto duplo processo interativo que envolve o retratado, o fotógrafo e o observador da foto nos momentos que precedem o ato fotográfico e se sucedem a este. Interessa à reflexão aqui desenvolvida, considerar o portrait como campo de forças, capaz de materializar uma imagem convencionalmente tomada pela identidade de um indivíduo, mas também questionada pelo olhar que distancia a foto de qualquer referente e destaca sua composição e sua força enquanto imagem. Sem perder de vista o panorama histórico da representação humana, escolheu-se para formar o corpus da pesquisa a produção de portraits dos fotógrafos franceses do século XIX, Félix Nadar (1820-1910) e Eugène Disdéri (1819-1889). Os dois são considerados cânones da fotografia oitocentista, trabalharam durante o chamado período "de ouro" do gênero na França; e seus estilos influenciaram a fotografia no mundo inteiro, inclusive no Brasil. Esses fotógrafos dedicaram-se também às escritas autobiográfica e ensaística, objetos paralelos de trabalho interpretativo. O olhar com que o século XIX se dirigia ao portrait oscilava entre o reconhecimento da semelhança identificadora e a revelação da intimidade secreta. A perspectiva escolhida foi a de situar a intimidade e a semelhança na contraposição entre uma noção de "profundidade" proveniente da visão romântica e arraigada no senso comum e uma noção de "superfície”, a partir da ótica contemporânea que destitui o sujeito desse espaço profundo e o constrói na exterioridade, no "fora".

\section{Palavras-chave}

Portrait fotográfico, semelhança, intimidade, biografia, autobiografia, representação. 


\section{Résumé}

Bastos, Maria Teresa Ferreira; Cardoso, Marília Rothier (Advisor). Une enquête dans l'intimité du portrait photographique. Rio de Janeiro, 2007. 244p. Tese de Doutorado - Departamento de Letras. Pontifícia Universidade Católica do Rio de Janeiro.

Le but de cette thèse est le portrait photographique, examiné comme un genre de reproduction de l'image mais aussi comme un double processus interactif capable de réunir le portraituré, le photographe et le spectateur de la photo dans le moment qui précède et succède l’acte photographique. La réflexion développée ici s'intéresse à considérer le portrait comme un champ de forces capable de matérialiser une image conventionnellement prise par l'identité d'un individu, mais aussi questionnée par le regard qui éloigne la photo de tout référent et en détache sa composition et sa force, comme image. Sans perdre de vue le panorama historique de la représentation humaine par la photographie, on a choisi de faire des recherches à partir des œuvres de deux photographes français du XIX siècle: Félix Nadar (1820-1910) et Eugène Disdéri (1819-1889). Ils ont fourni une grande production d'images. Ils ont travaillé pendant l'âge d'or du genre en France. Leurs styles ont beaucoup influencé la photographie dans le monde entier. Ces photographes se sont dédié également aux écritures autobiographiques et d'essais, objets parallèles de travail interprétatif. Le regard du XIX siècle sur le portrait photographique oscillait entre la reconnaissance de la ressemblance identificatrice et la révélation de l'intimité secrète. La perspective choisie a été de travailler l’intimité dans la contreposition entre une notion de la “profondeur” du sujet, provenant de la vision romantique et enracinée dans le sens commun et une notion en “surface”, à partir de la position post-moderne qui destitue le sujet de l'espace profond et le construit en externe, en dehors.

\section{Mots clés}

Portrait photographique, biographie, représentation, autobiographie, intimité- ressemblance. 


\section{Sumário}

1. O portrait fotográfico como objeto de estudo 11

1.1. O mosaico 15

1.2. A escolha da cena francesa do século XIX 26

$\begin{array}{ll}\text { 1.3. A abordagem do assunto } & 29\end{array}$

2. O gênero portrait $\quad 32$

2.1. O portrait como identidade e como imagem autônoma 35

2.2. A intimidade $\quad 39$

2.3. O eu e o outro 43

3. Nadar e Disdéri: um duelo de estilos 45

$\begin{array}{ll}3.1 \text { A força do arquivo } & 50\end{array}$

3.2 Disdéri e a semelhança moral $\quad 54$

3.3 A semelhança intima de Nadar 67

$\begin{array}{ll}\text { 3.4 Auto-retratos: espelhos de estilo } & 75\end{array}$

4. Fotografia como arte $\quad 81$

4.1. Francis Wey 83

4.2.Gustave Le Gray, Nadar e a Sociedade Heliográfica 87

4.3. A crítica de Baudelaire $\quad 91$

4.4. Nadar e Baudelaire 93

4.5. Julia Cameron 100

5. Manuais de fotografia do século XIX 107

$\begin{array}{ll}\text { 5.1. Disdéri ensaísta } & 110\end{array}$

5.2. O manual como uma receita 113

5.3. O discurso em prol da fotografia como arte 117

6. Nadar: escritos e portraits 122

6.1. Quand j'étais photographe 125

6.2. Alguns portraits célebres 129

7. Os tipos anônimos do portrait burguês 141

7.1. A pose de corpo inteiro 146

7.2. O contraponto com a exatidão do portrait judiciário 151

7.3. Aproximação ao acervo de Disdéri e o portrait como teatro 154

$\begin{array}{ll}\text { 7.4. Os portraits de Disdéri } & 158\end{array}$

7.5. O impacto das oito imagens 170

8. O portrait fotográfico entre biografia e imagem autônoma 179

9. Referências bibliográficas 184

$\begin{array}{ll}\text { 10. Anexo } & 199\end{array}$ 


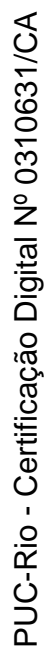

"Eu não conheço as pessoas. Eu as fotografo." Denise Colomb, Instantanés, 1999 